Article

\title{
Phenolic Compounds from Halimodendron halodendron (Pall.) Voss and Their Antimicrobial and Antioxidant Activities
}

\author{
Jihua Wang ${ }^{1}$, Jingfeng Lou ${ }^{1}$, Chao Luo ${ }^{1}$, Ligang Zhou ${ }^{1, *}$, Mingan Wang ${ }^{2, *}$ and Lan Wang ${ }^{3}$
}

1 College of Agronomy and Biotechnology, China Agricultural University, Beijing 100193, China; E-Mails: nxwjh8121@sina.com (J.W.); azaazafighting88@163.com (J.L.); luochaobest@163.com (C. L.)

2 College of Science, China Agricultural University, Beijing 100193, China

3 College of Plant Science, Tarim University, Alar 843300, Xinjiang, China; E-Mail: wang-lan95@163.com

* Authors to whom correspondence should be addressed; E-Mails: 1gzhou@cau.edu.cn (L.Z.); wangma@cau.edu.cn (M.W.); Tel.: +86 1062731199 (L.Z.); +86 1062734093 (M.W.).

Received: 26 July 2012; in revised form: 29 August 2012 / Accepted: 30 August 2012 /

Published: 12 September 2012

\begin{abstract}
Halimodendron halodendron has been used as forage in northwestern China for a long time. Its young leaves and flowers are edible and favored by indigenous people. In this study, eleven phenolic compounds were bioassay-guided and isolated from the aerial parts of $H$. halodendron for the first time. They were identified by means of physicochemical and spectrometric analysis as quercetin (1), 3,5,7,8,4'-pentahydroxy-3'-methoxy flavone (2), 3-O-methylquercetin (3), 3,3'-di- $O$-methylquercetin (4), 3,3'-di- $O$-methylquercetin-7- $O$ - $\beta$-D-glucopyranoside (5), isorhamentin-3-O- $\beta$-D-rutinoside (6), 8-O-methylretusin (7), 8- $O$-methylretusin-7- $O$ - $\beta$-Dglucopyranoside (8), salicylic acid (9), $p$-hydroxybenzoic acid (ferulic acid) (10), and 4-hydroxy-3-methoxy cinnamic acid (11). They were sorted as flavonols (1-6), soflavones (7 and 8), and phenolic acids (9-11). Among the compounds, flanools 1-4 revealed a strong antibacterial activity with minimum inhibitory concentration (MIC) values of $50-150 \mu \mathrm{g} / \mathrm{mL}$, and median inhibitory concentration $\left(\mathrm{IC}_{50}\right)$ values of 26.8-125.1 $\mu \mathrm{g} / \mathrm{mL}$. The two isoflavones (7 and 8) showed moderate inhibitory activity on the test bacteria. Three phenolic acids (9, 10 and 11) showed strong antibacterial activity with $\mathrm{IC}_{50}$ values of $28.1-149.7 \mu \mathrm{g} / \mathrm{mL}$. Antifungal activities of the compounds were similar to their antibacterial activities. All these phenolic compounds showed significant antimicrobial activity with a broad spectrum as well as antioxidant activity based on
\end{abstract}


1,1-diphenyl-2-picrylhydrazyl (DPPH) radical scavenging and $\beta$-carotene-linoleic acid bleaching assays. In general, the flavonol aglycones with relatively low polarity exhibited stronger activities than the glycosides. The results suggest the potential of this plant as a source of functional food ingredients and provide support data for its utilization as forage as well.

Keywords: Halimondendron halodendron; phenolic compounds; antimicrobial activity; antioxidant activity

\section{Introduction}

Antioxidants play important roles in scavenging free radicals and/or chain breaking the oxidation reactions both in vitro and in vivo to minimize oxidative damages to the cells [1]. However, the application of synthetic antioxidants, such as butylated hydroxytoluene (BHT), butylated hydroxylanisole (BHA), and propyl gallate in foods has led to notable adverse effects in consumer health [2,3]. Microbial contamination is another common problem in the food, cosmetic and pharmaceutical industries and the resistance to existing antimicrobial agents creates the need for new antimicrobial compounds. In recent years, there has been an increasing interest in the exploration of naturally occurring antioxidants and antimicrobials from various sources. The plant kingdom produces a diverse array of natural compounds, many of which have strong antioxidant and antimicrobial activities and have been used as food additives, pharmaceuticals and cosmetic components [4]. Phenolic compounds from plants constitute one of the most important groups of natural products with multi-beneficial bioactivities, such as antioxidant [5,6], anti-carcinogenic [7], anti-microbial [8-10], anti-mutagenic [11], anti-inflammatory [12], anti-allergic [13] and anti-obesity [14] properties.

Halimodendron halodendron (Pall.) Voss, a leguminous species mainly distributed in the provinces of Xinjiang, Gansu and Inner Mongolia of northwestern China, has been used as forage with good nutrition in desert areas for a long time [15]. The young leaves and flowers are edible and favored by indigenous people [16]. It is possible that H. halodendron contains bioactive components that contribute to good health. To the best of our knowledge, there is little information of its chemical composition and bioactivity except for our previous studies about the preparative separation of the main phenolic compounds by high-speed countercurrent chromatography (HSCCC) [17] and bioactivities of the flower essential oil [18]. Other investigations into this plant included a few phylogenic and cytological studies $[19,20]$. In this context, this study was to isolate and identify the main phenolic compounds from the aerial parts of this plant and to evaluate their antioxidant and antimicrobial activities in order to provide supporting data for the development and utilization of H. halodendron. 


\section{Results and Discussion}

\subsection{Elucidation of the Purified Phenolic Compounds}

Eleven compounds were bioassay-guided and isolated from the crude ethanol extract of $H$. halodendron (aerial parts) and characterized based on the physicochemical properties and spectral data. Their chemical structures were elucidated based on the spectral data and comparison of the properties and spectral characteristics with those in the literature, which were all known compounds and confirmed as quercetin (1) [21], 3,5,7,8,4'-pentahydroxy-3'-methoxy flavone (2) [22], 3-O-methylquercetin (3) [23], 3,3'-di-O-methylquercetin (4) [24], 3,3'-di- $O$-methylquercetin-7-O- $\beta$-Dglucopyranoside (5) [25], isorhamentin-3-O- $\beta$-D-rutinoside (6) [26], 8-O-methylretusin (7) [27], 8-O-methylretusin-7-O- $\beta$-D-glucopyranoside (8) [28], salicylic acid (9) [9], $p$-hydroxybenzoic acid (10) [29], and 4-hydroxy-3-methoxy cinnamic acid (ferulic acid) (11) [30] (Figure 1). Of the 11 compounds, 1-6 were flavonol derivatives, 7 and $\mathbf{8}$ were isoflavone derivatives, and 9, 10 and 11 were phenolic acids. Compound 6 should be derived from 4 with the methoxy group at Position 3 being substituted by rutinose, Compound $\mathbf{8}$ derived from 7 with the hydroxyl group at Position 7 glycosilated with glucose, and Compound 5 derived from $\mathbf{4}$ with the hydroxyl group at Position 7 glycosilated with glucose.

Figure 1. Chemical structures of the compounds (1-11).

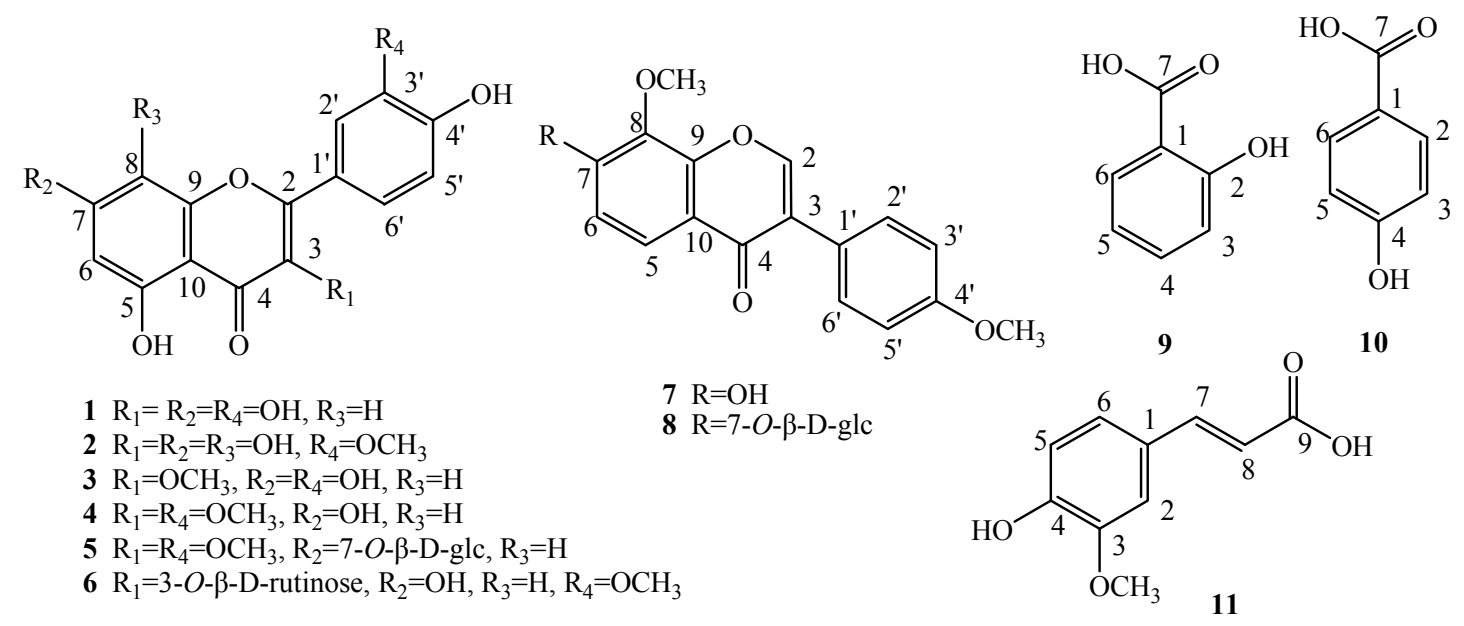

\subsection{Antibacterial Activity}

All the phenolic compounds were tested for antibacterial activities and their minimum inhibitory concentration (MIC) and median inhibitory concentration $\left(\mathrm{IC}_{50}\right)$ values are reported in Figure 2 . Of the six flavonols, only four aglycones, i.e. quercetin (1), 3,5,7,8,4'-pentahydroxy-3'-methoxy flavone (2), 3-O-methylquercetin (3) and 3,3'-di- $O$-methylquercetin (4), revealed strong antibacterial activity with relatively low MIC values of $50-150 \mu \mathrm{g} / \mathrm{mL}$, and low $\mathrm{IC}_{50}$ values of $26.8-125.1 \mu \mathrm{g} / \mathrm{mL}$. Their glycosides, i.e., 3,3'-di- $O$-methylquercetin-7- $O$ - $\beta$-D-glucopyranoside (5) and isorhamentin-3- $O$ - $\beta$-D-rutinoside (6), exhibited weak antibacterial activity with $\mathrm{MIC}$ values of $250-400 \mu \mathrm{g} / \mathrm{mL}$, and $\mathrm{IC}_{50}$ values of $168.7-297.7 \mu \mathrm{g} / \mathrm{mL}$. The two isoflavones 8 - $O$-methylretusin (7) and 8-O-methylretusin-7-O- $\beta$-D-glucopyranoside (8) showed moderate inhibitory activity on the test 
bacteria. Three phenolic acids $\left(\mathbf{9}, \mathbf{1 0}\right.$ and 11) showed strong antibacterial activity with $\mathrm{IC}_{50}$ values of 28.1-149.7 $\mu \mathrm{g} / \mathrm{mL}$. There were no obvious differences for the compounds against Gram-positive and negative bacteria.

Figure 2. Minimum inhibitory concentration (MIC) (A) and median inhibitory concentration $\left(\mathrm{IC}_{50}\right)(\mathbf{B})$ of the phenolic compounds from $H$. halodendron on bacteria. A. tum.: Agrobacterium tumefaciens; E. coli: Escherichia coli; P. lach.: Pseudomonas lachrymans; X. vesic.: Xanthomonas vesicatoria; B. sub.: Bacillus subtilis; S. aur.: Staphyloccocus aureus; S. haem.: Staphylococcus haemolyticus; Strep: streptomycin sulfate.

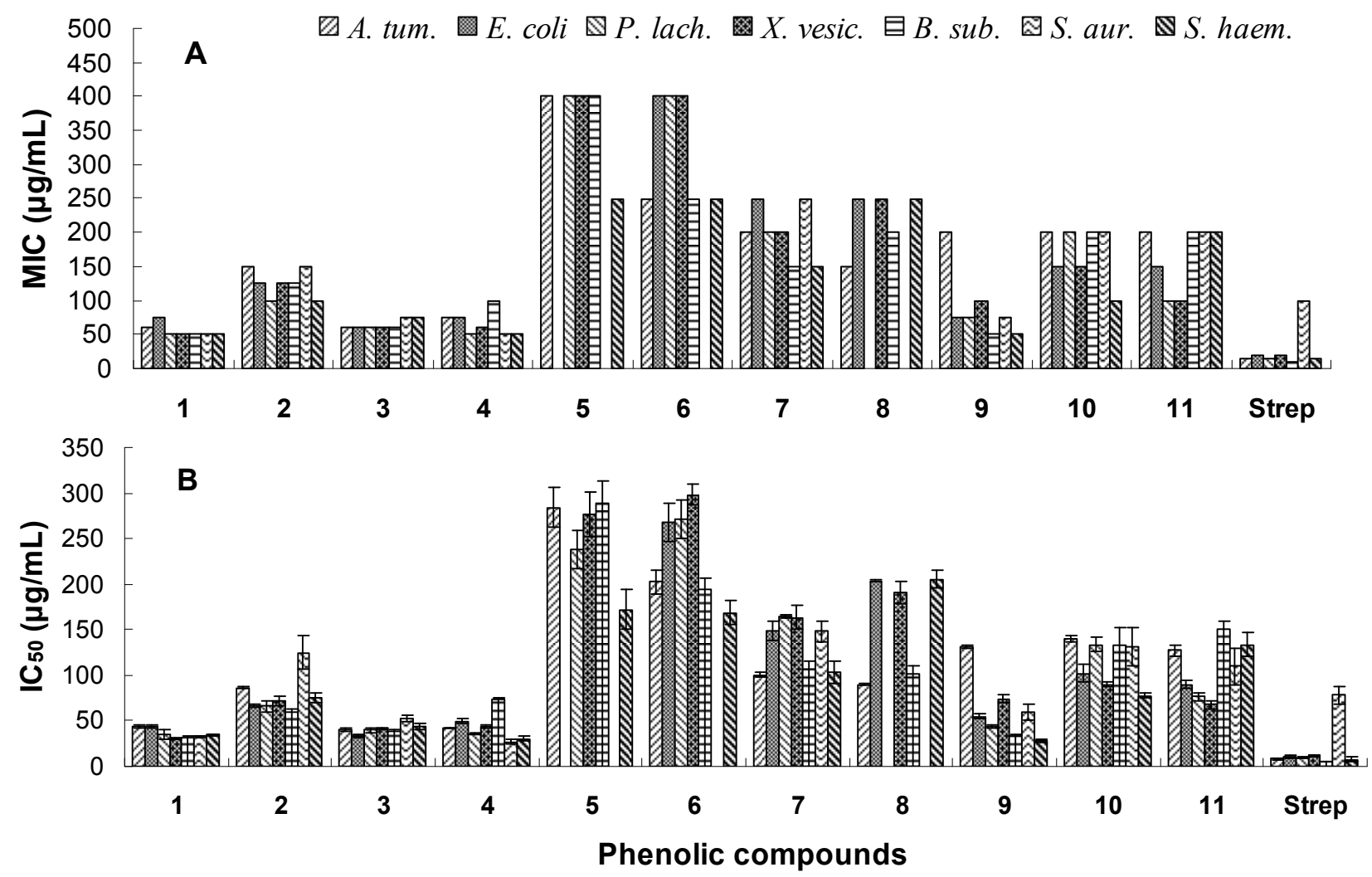

\subsection{Antifungal Activity}

The antifungal activity of the phenolic compounds with their $\mathrm{MIC}$ and $\mathrm{IC}_{50}$ values shown in Figure 3 was similar to the antibacterial activity. Compounds 1, 3, 4 and 7 had the highest inhibitory activities on $M$. oryzae spore germination with the lowest $\mathrm{IC}_{50}$ values of 35.80-67.90 $\mu \mathrm{g} / \mathrm{mL}$. Glycosides 5, 6 and $\mathbf{8}$ only exhibited weak activity with relatively high $\mathrm{IC}_{50}$ values of $182.9-264.7 \mu \mathrm{g} / \mathrm{mL}$. The three phenolic acids showed moderate inhibitory activity with $\mathrm{IC}_{50}$ values of $99.1-167.5 \mu \mathrm{g} / \mathrm{mL}$. All tested phenolic compounds exhibited moderate antifungal activity on Candida albicans, most of which were even stronger than the positive control amphotericin B, except for Compounds $\mathbf{5}$ and $\mathbf{6}$ showing no activity. The results suggest that the fungus Candida albicans is an amphotericin-resistant strain and these phenolic compounds are potential antifungal agents against amphotericin-resistant C. albicans.

The structure and antimicrobial activity relationships of the six flavonol compounds suggest that aglycones have stronger inhibitory activities on both bacteria and fungi than their glycosides. In addition, Compounds 1, 3 and $\mathbf{4}$ also had strong antibacterial activity, suggesting that the hydroxyl or 
methoxyl groups at the C-3, C-5, C-7, C-3' and C-4' positions may be essential to the antibacterial activity of the flavonoids. Indeed, Tsuchiya et al. suggested that 2',4'- or 2',6'-dihydroxylation of the ring $\mathrm{B}$ and 5,7-dihydroxylation of the ring $\mathrm{A}$ in the flavanone structure was important for anti-methicillin resistant Staphylococcus aureus (MRSA) activity [31]. Kaul et al. showed that 4-hydroxy-3-methoxyflavones with a polysubstituted ring A exhibited higher antiviral activity than the same type of compounds with a monosubstituted ring A [32]. Osawa et al. also showed, based on the activities detected of several structurally different flavonoids including flavones, flavanones, isoflavones and isoflavanones, that 5-hydroxyflavanones and 5-hydroxyisoflavanones with one, two or three additional hydroxyl groups at the 7,2' and 4' positions could significantly inhibit the growth of Streptococcus mutans and S. sobrinus [33]. Monosubstitution in ring B was probably contributable to the moderate inhibitory activity of the two isoflavonoids (7 and 8) as previously suggested by Kaul et al. [32]. Salicylic acid (9) showed higher antimicrobial activity than $p$-hydroxybenzoid acid (10) except on Candida albicans. This suggests that the ortho-substituted hydroxyl group was more important than the para-substituted hydroxyl group for the antimicrobial activity of the phenolic acids.

Figure 3. Minimum inhibitory concentration (MIC) (A) and median inhibitory concentration $\left(\mathrm{IC}_{50}\right)(\mathbf{B})$ of the phenolic compounds from $H$. halodendron on the test fungi. The positive controls $(\mathrm{CK}+)$ for Candida albicans and Magnaporthe oryzae were amphotericin B and carbendazim, respectively.

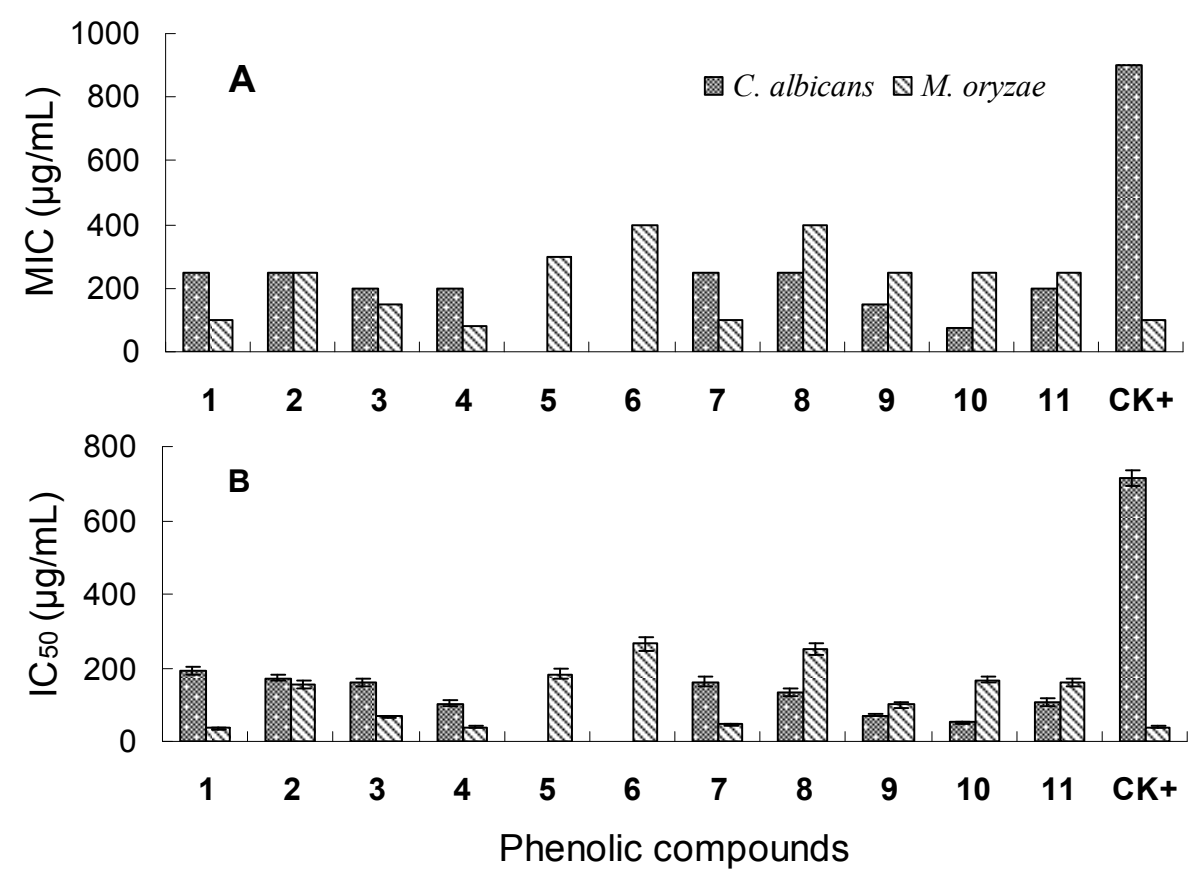

\subsection{Antioxidant Activity}

Figure 4 shows the $\mathrm{IC}_{50}$ values of the phenolic compounds in the DPPH radical scavenging and $\beta$-carotene-linoleic acid bleaching assays. In view of the $\mathrm{IC}_{50}$ values in the DPPH assay, the radical scavenging activities of the six flavonol compounds were in order of quercetin (1) $\left(\mathrm{IC}_{50}\right.$ of $\left.7.4 \mu \mathrm{g} / \mathrm{mL}\right)$ and 3-O-methylquercetin (3) ( $\mathrm{IC}_{50}$ of $\left.7.2 \mu \mathrm{g} / \mathrm{mL}\right)>3,5,7,8,4$ '-pentahydroxy-3'-methoxy flavone (2) $\left(\mathrm{IC}_{50}\right.$ of $\left.16.3 \mu \mathrm{g} / \mathrm{mL}\right)>3,3^{\prime}$-di-O-methylquercetin $\quad$ (4) $\left(\mathrm{IC}_{50}\right.$ of $\left.143.9 \mu \mathrm{g} / \mathrm{mL}\right) \quad>$ 
3,3'-di- $O$-methylquercetin-7-O- $\beta$-D-glucopyranoside

$\left(\mathrm{IC}_{50}\right.$ of

$216.7 \mu \mathrm{g} / \mathrm{mL}) \quad>$ isorhamentin-3-O- $\beta$-D-rutinoside $(6)\left(\mathrm{IC}_{50}\right.$ of $\left.525.5 \mu \mathrm{g} / \mathrm{mL}\right)$. Three phenolic acids had relatively high radical scavenging activities with relatively low $\mathrm{IC}_{50}$ values of $48.0-156.3 \mu \mathrm{g} / \mathrm{mL}$, while the two isoflavones (7 and 8) had very low activities with $\mathrm{IC}_{50}$ values of $587.2 \mu \mathrm{g} / \mathrm{mL}$ and $471.5 \mu \mathrm{g} / \mathrm{mL}$.

Figure 4. Antioxidant activity of the phenolic compounds of $H$. halodendron measured by 1,1-diphenyl-2-picrylhydrazyl (DPPH) inhibition (A) and $\beta$-carotene bleaching (B) assays. The positive control for the assays was butylated hydroxytoluene (BHT). The error bars represent standard deviations $(n=3)$. Different letters indicate significant differences among the treatments at $p=0.05$ level.

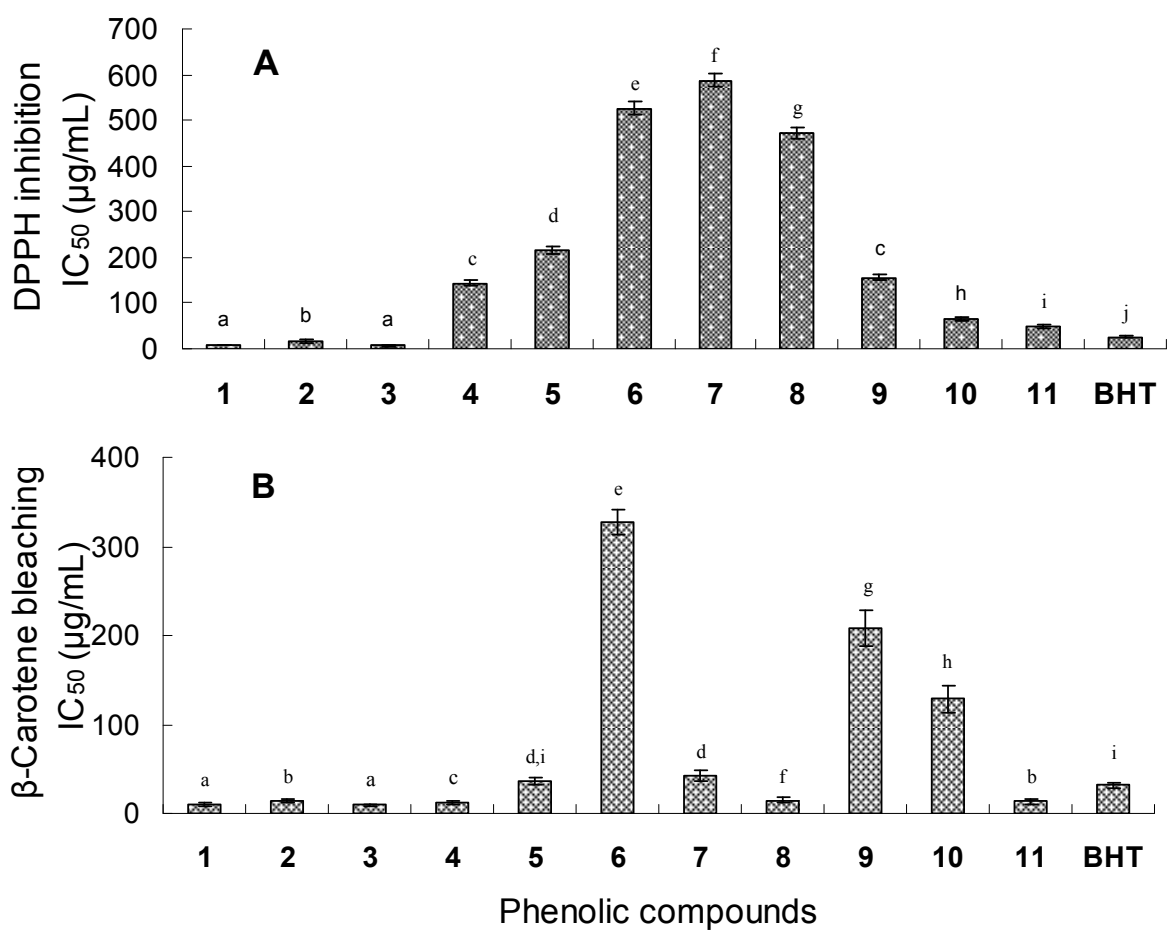

In the $\beta$-carotene-linoleic acid assay, most of the flavonol compounds exhibited a strong quenching activity with low $\mathrm{IC}_{50}$ values of $9.5-36.4 \mu \mathrm{g} / \mathrm{mL}$ except Compound 6 with a high $\mathrm{IC}_{50}$ value of $326.5 \mu \mathrm{g} / \mathrm{mL}$. The three phenolic compounds $(\mathbf{9}, \mathbf{1 0}$ and 11) also showed relatively high antioxidant activity with $\mathrm{IC}_{50}$ of $13.4-128.9 \mu \mathrm{g} / \mathrm{mL}$. The $\beta$-carotene-linoleic acid assay is based on the antioxidant protection of $\beta$-carotene from oxidation or bleaching by peroxyl radicals [34]. The antioxidant activity results of the six flavonols from this assay showed a high consistency with those from the DPPH radical assay that aglycones were more favorable than their glycosides. However, the two isoflavones (7 and 8) had a strong activity to inhibit the bleaching of $\beta$-carotene but low activity in scavenging DPPH radicals.

The structure-antioxidant activity relationships of flavonoids have been widely investigated based on chemical antioxidant activity assays [35-37]. Among the determinants of antioxidant capacity of flavonoids are the presence of a catechol group in Ring B, which is a radical target with stronger electron donating properties, a 2,3-double bond conjugated with the 4-oxo group, which is responsible for electron delocalization, and the presence of hydroxyl groups at C-3 and C-5 positions [38-41]. In our study, Compounds $\mathbf{1}$ and $\mathbf{3}$ with the highest antioxidant activities were probably attributable to the 
3',4'-dihydroxy structure, which has a catechol in Ring B. On the other hand, the inhibition potency was not reduced with the substitution of hydroxyl group at C-3 position by methoxy (e.g. compound 3). Pietta suggested that the presence of a 3-hydroxyl group in Ring $\mathrm{C}$ also increased the radical-scavenging activity, while additional hydroxyl or methoxyl groups at C-3, C-5 and C-7 positions of Rings $\mathrm{C}$ and A were less important [42]. In other words, the antioxidant activity of natural flavonoids is governed by both the number and the location of their aromatic hydroxyl groups [43]. When those substituted groups were glycosilated, their antiradical activities were obviously lowered, as it was the case for Compounds $\mathbf{5}$ and $\mathbf{6}$, which showed weak radical scavenging activity in this study.

\section{Experimental Section}

\subsection{Plant Materials}

The aerial parts of Halimodendron halodendron were collected in June 2008 in Shihezi, Xinjiang, China. The plant was authenticated by Professor Ping Yan at Shihezi University, where the voucher specimen of the plant materials was deposited. The plant materials were left to dry in the shade at room temperature to a constant weight.

\subsection{Solvents and Chemicals}

Beta-carotene, carbendazim, streptomycin sulfate, and 2,2-diphenyl-1-picrylhydrazyl (DPPH) were purchased from Sigma-Aldrich (USA). Linoleic acid was obtained from Johnson Matthey (UK). Amphotericin B and 3-(4,5-dimethylthiazol-2-yl)-2,5-diphenyl tetrazolium bromide (MTT) were purchased from Amresco (USA). Butylated hydroxytoluene (BHT) and Tween-40 were from Beijing Chemical Company. All other unlabelled chemicals and reagents were of analytical grade.

\subsection{General Analytical Methods}

Silica gel (100-200 and 200-300 mesh, Qingdao Marine Chemical Company, China), Sephadex LH-20 (Pharmacia), and $\mathrm{C}_{18}$ reversed-phase silica gel (200-300 mesh, YMC) were used for column chromatography (CC). Analytical and preparative thin-layer chromatography (TLC) plates were coated with $0.5 \mathrm{~mm}$ and $1 \mathrm{~mm}$ layers of silica gel $\mathrm{GF}_{254}$, respectively (400 mesh, Qingdao Marine Chemical Company, China). Macroporous resin AB-8 was purchased from Haiguang Chemical Industrial Company (Tianjin, China). The melting point was determined on an XT4-100B microscopic melting-point apparatus (Tianjin Tianguang Optical Instruments Company, China). NMR was recorded on a Bruker-ARX-300 spectrometer $\left({ }^{1} \mathrm{H}\right.$ at $300 \mathrm{MHz}$ and ${ }^{13} \mathrm{C}$ at $\left.75 \mathrm{MHz}\right)$ and Bruker Avance DRX-500 ( ${ }^{1} \mathrm{H}$ at $500 \mathrm{MHz}$ and ${ }^{13} \mathrm{C}$ at $125 \mathrm{MHz}$ ). Electrospray ionization mass spectrometry (ESI-MS) was performed on a Bruker Esquire $6000 \mathrm{LC} / \mathrm{MS}$ spectrometer and electron impact mass spectrometry (EI-MS) on a Thermo Finnigan LCQ mass spectrometer. Absorbance of the samples was measured with a microplate spectrophotometer (PowerWave HT, BioTek Instruments). 


\subsection{Extraction and Fractionation of the Compounds from Plant Materials}

The dry aerial parts of $H$. halodendron were ground into powder with a grinder, and $8 \mathrm{~kg}$ of the powder was soaked in $95 \%$ ethanol at room temperature three times at an interval of 10 days $(3 \times 30 \mathrm{~L})$. After filtration, the filtrate was concentrated under vacuum at $50{ }^{\circ} \mathrm{C}$, the brown residue $(1000 \mathrm{~g}$, yield $12.5 \%, w / w)$ was suspended in water and extracted with petroleum ether and chloroform successively. The chloroform extract ( $12 \mathrm{~g}$, yield $0.15 \%, w / w$ ) was subjected to silica gel column chromatography and eluted with petroleum ether-acetone (from 1:0 to 1:1, v/v; about 5-fold of the column volume for each eluent), yielding five fractions as detected by TLC. Of these, one fraction (230 mg) was repeatedly chromatographed with silica gel and then purified with Sephadex LH-20 to afford Compounds 4 (16 mg) and 7 (25 mg). The aqueous layer was subjected to macroporous resin AB-8 column chromatography, eluted with water, then with $30 \%$ ethanol and finally with $90 \%$ ethanol. The volume of each eluent was about five-fold that of the column volume. The fraction eluted out with $90 \%$ ethanol was further subjected to silica gel column chromatography eluted with $\mathrm{CHCl}_{3}-\mathrm{MeOH}-\mathrm{H}_{2} \mathrm{O} \quad(6: 1: 0.1, v / v)$, yielding five fractions. These fractions were repeatedly chromatographed with silica gel and then purified with Sephadex LH-20 and reverse phase chromatography (RP-18) to afford Compounds $\mathbf{1}$ (23 mg), 2 (20 mg), 3 (200 mg), 5 (12 mg), $\mathbf{6}(14 \mathrm{mg}), \mathbf{8}(16 \mathrm{mg}), \mathbf{9}(10 \mathrm{mg}), \mathbf{1 0}(13 \mathrm{mg})$ and $\mathbf{1 1}(21 \mathrm{mg})$.

\subsection{Physicochemical and Spectrometric Data of the Compounds}

Compound 1 was isolated as a yellow amorphous powder $(\mathrm{MeOH}) ; \mathrm{mp} 314-315{ }^{\circ} \mathrm{C}$; $\mathrm{UV}(\mathrm{MeOH})$, $\lambda_{\max } 255,372 \mathrm{~nm}$; ESI-MS m/z $303[\mathrm{M}+\mathrm{H}]^{+}, 301[\mathrm{M}-\mathrm{H}]^{-} ;{ }^{1} \mathrm{H}$ NMR (DMSO- $\left.d_{6}, 300 \mathrm{MHz}\right) \delta(\mathrm{ppm}):$ 9.38 (1H, s, OH-3), 12.49 (1H, s, OH-5), 6.19 (1H, d, J=2.0 Hz, H-6), 10.77 (1H, s, OH-7), 6.42 (1H, d, $J=2.0 \mathrm{~Hz}, \mathrm{H}-8), 7.68\left(1 \mathrm{H}, \mathrm{d}, J=2.2 \mathrm{~Hz}, \mathrm{H}-2^{\prime}\right), 9.38\left(1 \mathrm{H}, \mathrm{s}, \mathrm{OH}-3^{\prime}\right), 9.38\left(1 \mathrm{H}, \mathrm{s}, \mathrm{OH}-4^{\prime}\right), 6.90(1 \mathrm{H}$, $\left.\mathrm{d}, J=8.5 \mathrm{~Hz}, \mathrm{H}-5^{\prime}\right), 7.56\left(1 \mathrm{H}, \mathrm{dd}, J=2.2,8.5 \mathrm{~Hz}, \mathrm{H}-6{ }^{\prime}\right) ;{ }^{13} \mathrm{C}$ NMR (DMSO- $\left.d_{6}, 125 \mathrm{MHz}\right) \delta(\mathrm{ppm})$ : 147.9 (C-2), 135.8 (C-3), 176.0 (C-4), 160.8 (C-5), 98.3 (C-6), 164.1 (C-7), 93.5 (C-8), 156.3 (C-9), 103.1 (C-10), 122.1 (C-1'), 115.2 (C-2'), 145.2 (C-3'), 146.9 (C-4'), 115.7 (C-5'), 120.1 (C-6'). Those data were consistent with the literature [21]. Therefore, Compound 1 was identified as quercetin.

Compound 2 was isolated as a yellow amorphous powder $(\mathrm{MeOH}) ; \mathrm{mp} 272-278{ }^{\circ} \mathrm{C}$; $\mathrm{UV}(\mathrm{MeOH})$, $\lambda_{\max } 259,379 \mathrm{~nm}$; ESI-MS $m / z 333[\mathrm{M}+\mathrm{H}]^{+}, 331[\mathrm{M}-\mathrm{H}]^{-} ;{ }^{1} \mathrm{H}$ NMR (DMSO- $\left.d_{6}, 300 \mathrm{MHz}\right) \delta(\mathrm{ppm})$ : $9.50(1 \mathrm{H}, \mathrm{s}, \mathrm{OH}-3), 12.17(1 \mathrm{H}, \mathrm{s}, \mathrm{OH}-5), 6.27(1 \mathrm{H}, s, \mathrm{H}-6), 9.50(1 \mathrm{H}, \mathrm{s}, \mathrm{OH}-7), 9.50(1 \mathrm{H}, \mathrm{s}, \mathrm{OH}-8)$, $7.72\left(1 \mathrm{H}, \mathrm{d}, J=2.2 \mathrm{~Hz}, \mathrm{H}-2^{\prime}\right), 3.84\left(3 \mathrm{H}, \mathrm{s}, \mathrm{OCH}_{3}-3^{\prime}\right), 9.50\left(1 \mathrm{H}, \mathrm{s}, \mathrm{H}-4^{\prime}\right), 6.92\left(1 \mathrm{H}, \mathrm{d}, J=8.5 \mathrm{~Hz}, \mathrm{H}-5^{\prime}\right)$, $7.61(1 \mathrm{H}, \mathrm{dd}, J=2.2,8.5 \mathrm{~Hz}, \mathrm{H}-6)$ ) ${ }^{13} \mathrm{C}$ NMR (DMSO- $\left.d_{6}, 125 \mathrm{MHz}\right) \delta(\mathrm{ppm}): 147.9$ (C-2), $135.91(\mathrm{C}-3)$, 176.1 (C-4), 156.5 (C-5), 98.5 (C-6), 155.5 (C-7), 127.7 (C-8), 148.6 (C-9), 103.1 (C-10), 122.3 (C-1'), $115.1 \quad\left(\mathrm{C}-2^{\prime}\right), \quad 145.3 \quad\left(\mathrm{C}-3^{\prime}\right), \quad 61.2 \quad\left(\mathrm{OCH}_{3}-3^{\prime}\right), \quad 146.9 \quad\left(\mathrm{C}-4^{\prime}\right), \quad 115.8 \quad\left(\mathrm{C}-5^{\prime}\right), \quad 120.1 \quad\left(\mathrm{C}^{\prime}-6^{\prime}\right)$. Those data were consistent with the literature [22]. Therefore, Compound $\mathbf{2}$ was identified as 3,5,7,8,4'-pentahydroxy-3'-methoxy flavone.

Compound 3 was isolated as a yellow and needle crystal $(\mathrm{MeOH}) ; \mathrm{mp} 256-257^{\circ} \mathrm{C}$; $\mathrm{UV}(\mathrm{MeOH})$, $\lambda_{\max } 256,358 \mathrm{~nm}$; ESI-MS $m / z 315[\mathrm{M}-\mathrm{H}]^{-} ;{ }^{1} \mathrm{H}$ NMR (DMSO- $\left.d_{6}, 300 \mathrm{MHz}\right) \delta(\mathrm{ppm}): 3.78(3 \mathrm{H}, \mathrm{s}$, $\left.\mathrm{OCH}_{3}-3\right), 12.71(1 \mathrm{H}, \mathrm{s}, \mathrm{OH}-5), 6.20(1 \mathrm{H}, \mathrm{d}, J=2.0 \mathrm{~Hz}, \mathrm{H}-6), 10.82(1 \mathrm{H}, \mathrm{s}, \mathrm{OH}-7), 6.41(1 \mathrm{H}, \mathrm{d}, J=2.1 \mathrm{~Hz}$, H-8), $7.56\left(1 \mathrm{H}, \mathrm{d}, J=2.2 \mathrm{~Hz}, \mathrm{H}-2^{\prime}\right), 10.82\left(1 \mathrm{H}, \mathrm{s}, \mathrm{OH}-3^{\prime}\right), 10.82\left(1 \mathrm{H}, \mathrm{s}, \mathrm{OH}-4{ }^{\prime}\right), 6.92(1 \mathrm{H}, \mathrm{d}, J=8.5 \mathrm{~Hz}$, 
H-5'), 7.47 (1H, dd, $J=2.3,8.4 \mathrm{~Hz}, \mathrm{H}-6$ '); ${ }^{13} \mathrm{C}$ NMR (DMSO- $\left.d_{6}, 75 \mathrm{MHz}\right) \delta(\mathrm{ppm}): 155.8(\mathrm{C}-2), 137.8$ (C-3), 178.0 (C-4), 161.4 (C-5), 93.7 (C-6), 164.3 (C-7), 98.7 (C-8), 156.5 (C-9), 104.3 (C-10), 121.0 (C-1'), 115.6 (C-2'), 145.4 (C-3') , $59.8\left(\mathrm{OCH}_{3}-3^{\prime}\right), 148.9$ (C-4'), 115.9 (C-5'), 120.7 (C-6'). Those data were consistent with the literature [23]. Therefore, Compound $\mathbf{3}$ was identified as 3-O-methylquercetin.

Compound 4 was isolated as a yellow and needle crystal (chloroform); mp 210-212 ${ }^{\circ} \mathrm{C}$; UV $(\mathrm{MeOH}), \lambda_{\max } 268,205 \mathrm{~nm}$; ESI-MS $m / z 329[\mathrm{M}-\mathrm{H}]^{-} ; 335[\mathrm{M}+\mathrm{Na}]^{+} ;{ }^{1} \mathrm{H}$ NMR (DMSO- $d_{6}, 300$ $\mathrm{MHz}) \delta(\mathrm{ppm}): 3.80\left(3 \mathrm{H}, \mathrm{s}, \mathrm{OCH}_{3}-3\right), 12.68(1 \mathrm{H}, \mathrm{s}, \mathrm{OH}-5), 6.20(1 \mathrm{H}, \mathrm{d}, J=2.0 \mathrm{~Hz}, \mathrm{H}-6), 10.82(1 \mathrm{H}, \mathrm{s}$, OH-7), $6.48(1 \mathrm{H}, \mathrm{d}, J=2.1 \mathrm{~Hz}, \mathrm{H}-8), 7.64\left(1 \mathrm{H}, \mathrm{d}, J=2.1 \mathrm{~Hz}, \mathrm{H}-2^{\prime}\right), 3.86\left(1 \mathrm{H}, \mathrm{s}, \mathrm{OCH}_{3}-3^{\prime}\right), 9.88(1 \mathrm{H}, \mathrm{s}$, OH-4'), 6.97 (1H, d, $\left.J=8.4 \mathrm{~Hz}, \mathrm{H}-5^{\prime}\right), 7.58\left(1 \mathrm{H}, \mathrm{dd}, J=2.1,8.4 \mathrm{~Hz}, \mathrm{H}-6^{\prime}\right) ;{ }^{13} \mathrm{C}$ NMR (DMSO- $d_{6}, 125$ $\mathrm{MHz}) \delta(\mathrm{ppm}): 155.6$ (C-2), 137.9 (C-3), $59.9\left(\mathrm{OCH}_{3}-3\right), 178.1$ (C-4), 161.4 (C-5), 94.0 (C-6), 164.3 (C-7), 98.8 (C-8), 156.5 (C-9), 104.4 (C-10), 122.4 (C-1'), 112.3 (C-2'), 150.0 (C-3'), $55.9\left(\mathrm{OCH}_{3}-3^{\prime}\right)$, $147.6\left(\mathrm{C}-4^{\prime}\right), 115.8\left(\mathrm{C}-5^{\prime}\right), 121.0\left(\mathrm{C}^{\prime} 6^{\prime}\right)$. Those data were consistent with the literature [24]. Therefore, Compound 4 was identified as 3,3'-di- $O$-methylquercetin.

Compound 5 was isolated as a yellow amorphous powder $(\mathrm{MeOH}) ; \mathrm{mp} 202-208{ }^{\circ} \mathrm{C}$; $\mathrm{UV}(\mathrm{MeOH})$, $\lambda_{\max } 255,355 \mathrm{~nm}$; ESI-MS $m / z 493[\mathrm{M}+\mathrm{H}]^{+} ;{ }^{1} \mathrm{H}$ NMR (DMSO- $\left.d_{6}, 500 \mathrm{MHz}\right) \delta(\mathrm{ppm}): 3.81(3 \mathrm{H}, \mathrm{s}$, $\left.\mathrm{OCH}_{3}-3\right), 12.58(1 \mathrm{H}, \mathrm{s}, \mathrm{OH}-5), 6.44(1 \mathrm{H}, \mathrm{d}, J=2.0 \mathrm{~Hz}, \mathrm{H}-6), 6.84(1 \mathrm{H}, \mathrm{d}, J=2.0 \mathrm{~Hz}, \mathrm{H}-8), 7.65(1 \mathrm{H}$, $\left.\mathrm{d}, J=2.0 \mathrm{~Hz}, \mathrm{H}-2^{\prime}\right), 3.85\left(1 \mathrm{H}, \mathrm{s}, \mathrm{OCH}_{3}-3^{\prime}\right), 6.97\left(1 \mathrm{H}, \mathrm{d}, J=8.5 \mathrm{~Hz}, \mathrm{H}-5^{\prime}\right), 7.61(1 \mathrm{H}, \mathrm{dd}, J=2.0,8.5$ $\mathrm{Hz}, \mathrm{H}-6$ '), 5.05(1H, d, $J=7.0 \mathrm{~Hz}$, glc-H-1); ${ }^{13} \mathrm{C}$ NMR (DMSO- $\left.d_{6}, 125 \mathrm{MHz}\right) \delta$ (ppm): 156.1(C-2), 138.2 (C-3), $59.9\left(\mathrm{OCH}_{3}-3\right), 178.3$ (C-4), 161.1 (C-5), 99.4 (C-6), 163.1(C-7), 95.0 (C-8), 156.2 (C-9), 106.1 (C-10), 120.8 (C-1'), 112.2 (C-2'), 150.2 (C-3'), $55.9\left(\mathrm{OCH}_{3}-3^{\prime}\right), 147.7$ (C-4'), 115.8 (C-5'), 122.5 (C-6'), 100.2 (glc-1), 73.3 (glc-2), 77.5 (glc-3), 69.8 (glc-4), 76.7(glc-5), 67.4 (glc-6). Those data were consistent with the literature [25]. Therefore, Compound 5 was identified as 3,3'-di-O-methylquercetin-7-O- $\beta$-D-glucopyranoside

Compound 6 was isolated as a yellow amorphous powder; mp $186-187^{\circ} \mathrm{C}$; $\mathrm{UV}(\mathrm{MeOH}), \lambda_{\max } 355$, $255 \mathrm{~nm}$; ESI-MS $m / z 623[\mathrm{M}-\mathrm{H}]^{-} ;, 647[\mathrm{M}+\mathrm{Na}]^{+} ;{ }^{1} \mathrm{H}$ NMR (DMSO- $\left.d_{6}, 300 \mathrm{MHz}\right) \delta(\mathrm{ppm}): 12.50$ $(1 \mathrm{H}, \mathrm{s}, \mathrm{OH}-5), 6.19(1 \mathrm{H}, \mathrm{d}, J=1.9 \mathrm{~Hz}, \mathrm{H}-6), 10.89(1 \mathrm{H}, \mathrm{s}, \mathrm{OH}-7), 6.41(1 \mathrm{H}, \mathrm{d}, J=1.8 \mathrm{~Hz}, \mathrm{H}-8), 7.86$ $\left(1 \mathrm{H}, \mathrm{d}, J=2.0 \mathrm{~Hz}, \mathrm{H}-2^{\prime}\right), 3.83\left(3 \mathrm{H}, \mathrm{s}, \mathrm{OCH}_{3}-3^{\prime}\right) 9.83\left(1 \mathrm{H}, \mathrm{s}, \mathrm{OH}-4^{\prime}\right), 6.92\left(1 \mathrm{H}, \mathrm{d}, J=8.4 \mathrm{~Hz}, \mathrm{H}-5^{\prime}\right)$, $7.53\left(1 \mathrm{H}, \mathrm{dd}, J=2.0,8.4 \mathrm{~Hz}, \mathrm{H}-6^{\prime}\right), 5.44(1 \mathrm{H}, \mathrm{d}, J=7.3 \mathrm{~Hz}, \mathrm{glc}-\mathrm{H}-1), 4.41(1 \mathrm{H}, \mathrm{d}, J=10.8 \mathrm{~Hz}$, rha-H-1), $0.98\left(1 \mathrm{H}, \mathrm{d}, J=5.6 \mathrm{~Hz}\right.$, rha-H-6); ${ }^{13} \mathrm{C}$ NMR (DMSO- $\left.d_{6}, 75 \mathrm{MHz}\right) \delta$ (ppm): $156.7(\mathrm{C}-2)$, 133.2 (C-3), 177.4 (C-4), 161.4 (C-5), 99.5 (C-6), 165.0 (C-7), 94.3 (C-8), 156.3 (C-9), 103.4 (C-10), 121.2 (C-1'), 113.5 (C-2'), 149.6 (C-3'), $55.9\left(\mathrm{OCH}_{3}-3^{\prime}\right), 147.1$ (C-4'), $115.5\left(\mathrm{C}-5^{\prime}\right), 122.4\left(\mathrm{C}-6^{\prime}\right), 101.6$ (glc-1), 74.5 (glc-2), 76.6 (glc-3), 70.8 (glc-4), 76.1 (glc-5), 67.0 (glc-6), 101.1 (rha-1), 70.5 (rha-2), 70.8 (rha-3), 72.0 (rha-4), 68.5 (rha-5), 17.8 (rha-6). Those data were consistent with the literature [26]. Therefore, Compound 6 was identified as isorhamentin-3-O- $\beta$-D-rutinoside.

Compound 7 was isolated as a colorless and needle crystal (petroleum ether -acetone); $\mathrm{mp} 215-216{ }^{\circ} \mathrm{C}$; UV (MeOH), $\lambda_{\max } 243,295 \mathrm{~nm}$; ESI-MS $m / z 321[\mathrm{M}+\mathrm{Na}]^{+}, 297[\mathrm{M}-\mathrm{H}]^{-} ;{ }^{1} \mathrm{H}$ NMR (DMSO- $d_{6}, 300$ MHz) $\delta(\mathrm{ppm}): 8.43$ (1H, s, H-2), $7.74(1 \mathrm{H}, \mathrm{d}, J=8.8 \mathrm{~Hz}, \mathrm{H}-5), 7.05$ (1H, d, $J=9.0 \mathrm{~Hz}, \mathrm{H}-6), 10.67$ $\left(1 \mathrm{H}\right.$, br s, OH-7), $3.88\left(3 \mathrm{H}, \mathrm{s}, \mathrm{OCH}_{3}-8\right), 7.53\left(1 \mathrm{H}, \mathrm{d}, J=8.8 \mathrm{~Hz}, \mathrm{H}-2^{\prime}\right), 7.00\left(1 \mathrm{H}, \mathrm{d}, J=8.8 \mathrm{~Hz}, \mathrm{H}-3^{\prime}\right)$, $3.79\left(3 \mathrm{H}, \mathrm{s}, \mathrm{OCH}_{3}-4^{\prime}\right), 7.00\left(1 \mathrm{H}, \mathrm{d}, J=8.8 \mathrm{~Hz}, \mathrm{H}-5^{\prime}\right), 7.53\left(1 \mathrm{H}, \mathrm{d}, J=8.8 \mathrm{~Hz}, \mathrm{H}-6{ }^{\prime}\right)$; ${ }^{13} \mathrm{C} \mathrm{NMR}$ $\left(\mathrm{DMSO}-d_{6}, 75 \mathrm{MHz}\right) \delta(\mathrm{ppm}): 153.2$ (C-2), 123.1 (C-3), 174.8 (C-4), 120.9 (C-5), 115.4 (C-6), 154.9 (C-7), 134.9 (C-8), $60.9\left(\mathrm{OCH}_{3}-8\right), 150.8$ (C-9), 117.6 (C-10), 124.3 (C-1'), 130.2 (C-2'), 113.7 
(C-3'), $159.1\left(\mathrm{C}^{\prime} 4^{\prime}\right) .55 .3\left(\mathrm{OCH}_{3}-4^{\prime}\right), 113.8\left(\mathrm{C}-5^{\prime}\right), 130.2\left(\mathrm{C}-6^{\prime}\right)$. Those data were consistent with the literature [27]. Therefore, Compound 7 was identified as 8-O-methylretusin.

Compound 8 was isolated as a white amorphous powder $(\mathrm{MeOH}) ; \mathrm{mp} 215-216{ }^{\circ} \mathrm{C}$; $\mathrm{UV}(\mathrm{MeOH})$, $\lambda_{\max } 204,255 \mathrm{~nm}$; ESI-MS $m / z 461[\mathrm{M}+\mathrm{H}]^{+}, 483[\mathrm{M}+\mathrm{Na}]^{+} .{ }^{1} \mathrm{H}$ NMR $\left(\mathrm{DMSO}-d_{6}, 300 \mathrm{MHz}\right) \delta$ (ppm): $8.48(1 \mathrm{H}, \mathrm{s}, \mathrm{H}-2), 7.82(1 \mathrm{H}, \mathrm{d}, J=9.0 \mathrm{~Hz}, \mathrm{H}-5), 7.38(1 \mathrm{H}, \mathrm{d}, J=9.2 \mathrm{~Hz}, \mathrm{H}-6), 3.94(3 \mathrm{H}, \mathrm{s}$, $\left.\mathrm{OCH}_{3}-8\right), 7.55\left(1 \mathrm{H}, \mathrm{d}, J=9.0 \mathrm{~Hz}, \mathrm{H}-2^{\prime}\right), 7.01\left(1 \mathrm{H}, \mathrm{d}, J=9.2 \mathrm{~Hz}, \mathrm{H}-3{ }^{\prime}\right), 3.82\left(3 \mathrm{H}, \mathrm{s}, \mathrm{OCH}_{3}-4^{\prime}\right), 7.01$ $\left(1 \mathrm{H}, \mathrm{d}, J=9.0 \mathrm{~Hz}, \mathrm{H}-5^{\prime}\right), 7.55\left(1 \mathrm{H}, \mathrm{d}, J=9.0 \mathrm{~Hz}, \mathrm{H}-6^{\prime}\right), 5.17(1 \mathrm{H}, \mathrm{d}, J=7.3 \mathrm{~Hz}, \mathrm{glc}-\mathrm{H}-1), 4.59(1 \mathrm{H}, \mathrm{t}$, $J=6.0 \mathrm{~Hz}$, glc-H-6). ${ }^{13} \mathrm{C}$ NMR (DMSO- $\left.d_{6}, 125 \mathrm{MHz}\right) \delta(\mathrm{ppm}): 154.0$ (C-2), 123.0 (C-3), 174.8 (C-4), 120.3 (C-5), 113.9 (C-6), 154.0 (C-7), $136.9(\mathrm{C}-8), 60.5\left(\mathrm{OCH}_{3}-8\right), 149.9$ (C-9), 119.3 (C-10), 123.9 (C-1'), 130.0 (C-2'), 113.6 (C-3'), 159.0 (C-4'). $55.1\left(\mathrm{OCH}_{3}-4^{\prime}\right), 113.9\left(\mathrm{C}-5^{\prime}\right), 130.0$ (C-6'), 100.5 (glc-1), 73.2 (glc-2), 76.7 (glc-3), 69.6 (glc-4), 77.2 (glc-5), 61.2 (glc-6). Those data were consistent with the literature [28]. Therefore, Compound 8 was identified as 8-O-methylretusin-7-O- $\beta$-D-glucopyranoside.

Compound 9 was isolated as a colorless and sheet crystal (lamellar crystal) (acetone); mp 157-158 ${ }^{\circ} \mathrm{C}$; UV (MeOH) $\lambda_{\max } 231,300 \mathrm{~nm} ;{ }^{1} \mathrm{H}$ NMR (acetone- $\left.d_{6}, 500 \mathrm{MHz}\right) \delta(\mathrm{ppm}): 6.95(1 \mathrm{H}, \mathrm{d}, J=9.0 \mathrm{~Hz}, \mathrm{H}-3$ ), $7.54(1 \mathrm{H}, \mathrm{m}, \mathrm{H}-4), 6.93(1 \mathrm{H}, \mathrm{t}, J=9.0 \mathrm{~Hz}, \mathrm{H}-5), 7.90(1 \mathrm{H}, \mathrm{dd}, J=9.0,1.5 \mathrm{~Hz}, \mathrm{H}-6)$. Those data were consistent with the literature [9]. Therefore, Compound 9 was identified as salicylic acid.

Compound 10 was isolated as a white amorphous powder $(\mathrm{MeOH}) ; \mathrm{mp} 210-213{ }^{\circ} \mathrm{C}$; $\mathrm{UV}(\mathrm{MeOH})$ $\lambda_{\max } 204,252 \mathrm{~nm} ;{ }^{1} \mathrm{H}$ NMR (acetone- $\left.d_{6}, 500 \mathrm{MHz}\right) \delta$ (ppm): $7.92(2 \mathrm{H}, \mathrm{d}, J=9.0 \mathrm{~Hz}, \mathrm{H}-2$ and H-6), $6.92(2 \mathrm{H}, \mathrm{d}, J=6.92 \mathrm{~Hz}, \mathrm{H}-3$ and H-5). Those data were consistent with the literature [29]. Therefore, Compound 10 was identified as $p$-hydroxybenzoic acid.

Compound 11 was isolated as a colorless needle crystal $(\mathrm{MeOH}) ; \mathrm{mp} 172-174{ }^{\circ} \mathrm{C}$; UV (MeOH), $\lambda_{\max } 202,315 \mathrm{~nm}$; EI-MS $m / z 194[\mathrm{M}]^{+} ;{ }^{1} \mathrm{H}$ NMR (DMSO- $\left.d_{6}, 300 \mathrm{MHz}\right) \delta(\mathrm{ppm}): 7.28(1 \mathrm{H}, \mathrm{d}, J=2.0 \mathrm{~Hz}$, $\mathrm{H}-2), 3.84\left(3 \mathrm{H}, \mathrm{s}, \mathrm{OCH}_{3}-3\right), 6.82(1 \mathrm{H}, \mathrm{d}, J=8.1 \mathrm{~Hz}, \mathrm{H}-5), 7.09(1 \mathrm{H}, \mathrm{dd}, J=8.2,1.9 \mathrm{~Hz}, \mathrm{H}-6), 7.46$ $(1 \mathrm{H}, \mathrm{d}, J=15.9 \mathrm{~Hz}, \mathrm{H}-7), 6.39(1 \mathrm{H}, \mathrm{d}, J=15.9 \mathrm{~Hz}, \mathrm{H}-8), 9.55(1 \mathrm{H}$, br s, OH-4), 12.18(1H, br s, $\mathrm{COOH})$. Those data were consistent with the literature [30]. Therefore, Compound 11 was identified as 4-hydroxy-3-methoxy cinnamic acid, also named ferulic acid.

\subsection{Antibacterial Activity Assay}

Antibacterial activity of the compounds was tested against three Gram-positive bacteria (Bacillus subtilis ATCC 11562, Staphylococcus aureus ATCC 6538 and Staphylococcus haemolyticus ATCC 29970) and four Gram-negative bacteria (Agrobacterium tumefaciens ATCC 11158, Escherichia coli ATCC 29425, Pseudomonas lachrymans ATCC 11921 and Xanthomonas vesicatoria ATCC 11633). All bacterial species were obtained from the microbial culture stock in the Department of Plant Pathology, China Agricultural University and maintained in LB medium at $28{ }^{\circ} \mathrm{C}$ for antibacterial tests. The bacteria were cultured in liquid LB medium (yeast extract $5 \mathrm{~g} / \mathrm{L}$, peptone $10 \mathrm{~g} / \mathrm{L}$, $\mathrm{NaCl} 5 \mathrm{~g} / \mathrm{L}, \mathrm{pH} 7.0$ ) overnight at $28^{\circ} \mathrm{C}$, and the bacterial suspension was diluted to $1 \times 10^{6} \mathrm{cfu} / \mathrm{mL}$ for the assay. The antibacterial activity of the compounds was determined with the modified broth dilution-colorimetric assay using the chromogenic reagent 3-(4,5-dimethylthiazol-2-yl)-2,5-diphenyl tetrazolium bromide (MTT) [44]. Briefly, each compound sample was dissolved in ethanol or dimethyl sulfoxide (DMSO) at an initial concentration of $5 \mathrm{mg} / \mathrm{mL}$, and was then diluted with $30 \%$ ethanol or $30 \%$ DMSO to various concentrations from $0.2 \mathrm{mg} / \mathrm{mL}$ to $4.0 \mathrm{mg} / \mathrm{mL}$. The sample solution $(10 \mu \mathrm{L})$ 
and the bacterial suspension $\left(90 \mu \mathrm{L}\right.$ at $\left.1 \times 10^{6} \mathrm{cfu} / \mathrm{mL}\right)$ were added into each well of a 96-well microplate. The solvent of sample solution (30\% ethanol or $30 \% \mathrm{DMSO})$ was included as a negative control and streptomycin sulfate as a positive control in the test. The plates were agitated on a plate shaker and then incubated in the dark at $28{ }^{\circ} \mathrm{C}$ for $24 \mathrm{~h}$, at which $10 \mu \mathrm{L}$ of MTT $(5 \mathrm{mg} / \mathrm{mL}$ in $0.2 \mathrm{~mol} / \mathrm{L}$ of pH 7.2 phosphate-buffered saline) was added into each well, and the plates were incubated for another $4 \mathrm{~h}$. The minimum inhibitory concentration (MIC) value was determined as reported previously [45]. For further determination of the $\mathrm{IC}_{50}$ values for antibacterial activity of the compounds, the incubated microplate was centrifuged at $1500 \mathrm{~g}$ for $20 \mathrm{~min}$ and the supernatant was aspirated. To each well in the microplate, $200 \mu \mathrm{L}$ of DMSO was added and incubated for $30 \mathrm{~min}$ to extract the colored formazan product. After centrifugation of the liquid, the supernatant (100 $\mu \mathrm{L}$ DMSO solution) in each well was transferred to a new 96-well microplate to measure the absorbance at $510 \mathrm{~nm}$ on a microplate spectrophotometer. The percentage (\%) of bacterial growth inhibition was determined by $\left[\left(A_{\mathrm{c}}-A_{\mathrm{t}}\right) / A_{\mathrm{c}}\right] \times 100$, where $A_{\mathrm{c}}$ and $A_{\mathrm{t}}$ were the average absorbance of six replicates of the negative controls and that of the compound sample, respectively. The median inhibitory concentration $\left(\mathrm{IC}_{50}\right.$ ) value was derived from the linear relation between the inhibitory probability and the concentration logarithm [46]. The $\mathrm{IC}_{50}$ value was expressed as the mean \pm standard deviation of triplicate experiments.

\subsection{Antifungal Activity Assay}

Two fungal species Candida albicans and Magnaporthe oryzae were selected for antifungal activity assay. The dilution-colorimetric assay was employed to evaluate antifungal activity of the compounds on Candida albicans ATCC 10321, which was obtained from the microbial culture stock in the Department of Plant Pathology, China Agricultural University. The C. albicans fungus was cultured in liquid potato dextrose (PD) medium overnight at $28{ }^{\circ} \mathrm{C}$, and the fungal suspension was diluted to $1 \times 10^{6} \mathrm{cfu} / \mathrm{mL}$. The compound solution was prepared the same as in the above antibacterial activity assay to the final concentrations ranging from 0.05 to $0.30 \mathrm{mg} / \mathrm{mL}$ containing $3 \%$ ethanol or $3 \%$ DMSO. Amphotericin B was used as the positive control and all other procedures were the same as for the antibacterial activity assay.

The spore germination assay was employed to evaluate antifungal activity of the compounds on rice blast fungus, Magnaporthe oryzae strain P131 which was provided by Prof. Youliang Peng of the Department of Plant Pathology at China Agricultural University. The fungus was maintained on oatmeal-tomato agar (oatmeal $30 \mathrm{~g} / \mathrm{L}$, tomato juice $150 \mathrm{~mL} / \mathrm{L}$, and agar $20 \mathrm{~g} / \mathrm{L}$ ) at $25^{\circ} \mathrm{C}$ and the fungal spores were prepared from seven-day-old cultures of $M$. oryzae as reported previously [47]. The sample solutions were made to final concentrations ranging from 0.05 to $0.5 \mathrm{mg} / \mathrm{mL}$ containing $5 \%(v / v)$ ethanol. The negative control was $5 \%$ ethanol and the positive control was carbendazim at concentrations ranging from 0.02 to $0.20 \mathrm{mg} / \mathrm{mL}$. Each treatment was performed in triplicate. The sample or control solution $(25 \mu \mathrm{L})$ was mixed with an equal volume of spore suspension containing $2 \times 10^{6}$ spores $/ \mathrm{mL}$ and was then placed on separate concave glass slides. The slides containing the spores were incubated in a moist chamber at $25^{\circ} \mathrm{C}$ for $7 \mathrm{~h}$, and then observed under the microscope for spore germination. About 100 spores per replicate were examined for spore germination. The percentage (\%) of spore germination inhibition was represented by $\left[\left(G_{\mathrm{c}}-G_{\mathrm{t}}\right) / G_{\mathrm{c}}\right] \times 100$, where $G_{\mathrm{c}}$ and 
$G_{\mathrm{t}}$ are the average germinated spore numbers in the negative control and in the sample-treated group, respectively.

\subsection{Antioxidant Activity Assays}

Antioxidant activity of the compounds was determined by DPPH radical scavenging and $\beta$-carotene-linoleic acid bleaching assays. DPPH radical scavenging activity was determined based on the reduction of a methanol solution of 1,1-diphenyl-2-picrylhydrazyl (DPPH) as reported by Ono et al. [48]. Briefly, $80 \mu \mathrm{L}$ of DPPH solution $(0.2 \mathrm{mg} / \mathrm{mL})$ and $20 \mu \mathrm{L}$ of each phenolic compound solution in $30 \%$ ethanol were added into each well of a 90 -well microplate. The microplate was shaken vigorously for complete mixing of the solution and left to stand at $37{ }^{\circ} \mathrm{C}$ for $30 \mathrm{~min}$ in the dark. The absorbance of the solution was then measured at $515 \mathrm{~nm}$ on a microplate spectrophotometer. Percentage (\%) of DPPH radical scavenging activity was calculated by $\left[\left(A_{\text {control }}-A_{\text {sample }}\right) / A_{\text {control }}\right] \times 100$, where $A_{\text {control }}$ is the absorbance of the control containing all reagents except the test sample, and $A_{\text {sample }}$ is the absorbance of the test sample. BHT was used as the positive control. The tests were performed in triplicate.

The $\beta$-carotene-linoleic acid bleaching assay of antioxidant activity was performed as reported previously [4]. Briefly, $25 \mu \mathrm{L}$ linoleic acid and $200 \mathrm{mg}$ Tween-40 were added into a $\beta$-carotene solution ( $0.5 \mathrm{mg} \beta$-carotene dissolved in $1 \mathrm{~mL}$ chloroform), followed by removal of the chloroform in a rotary evaporator at $50{ }^{\circ} \mathrm{C}$. The remaining mixture was mixed with $50 \mathrm{~mL}$ of oxygen-saturated distilled water by shaking vigorously. The $\beta$-carotene-linoleic acid-Tween mixture solution $(90 \mu \mathrm{L})$ and the sample compound solution $(10 \mu \mathrm{L}$ at various concentrations from $0.05 \mathrm{mg} / \mathrm{mL}$ to $4.0 \mathrm{mg} / \mathrm{mL})$ were added into each well of a 90 -well microplate. An equal volume of $30 \%$ ethanol was used as the blank. The microplate was placed in an incubator at $50{ }^{\circ} \mathrm{C}$ for $2 \mathrm{~h}$ together with BHT as the positive control. The absorbance solution was measured at $460 \mathrm{~nm}$ on a microplate spectrophotometer. The $\beta$-carotene bleaching inhibition activity of each sample was represented by the ratio of the absorbance of the mixture solution after $2 \mathrm{~h}$ of incubation to that of the initial mixture. All tests were performed in triplicate.

\subsection{Statistical Analysis}

The data were collected and expressed as the mean \pm standard deviation of three independent experiments. Analysis of variance (ANOVA) and the significance test of treatment effects were determined by Duncan's multiple range test at $p=0.05$ level.

\section{Conclusions}

In this study, eleven phenolic compounds including six flavonols (1-6), two isoflavones (7 and 8), and three phenolic acids (9-11) were bioassay-guided and isolated from the aerial parts of $H$. halodendron, and showed a broad spectrum of antimicrobial activity on several microorganisms including bacteria (Gram-positive and negative) and fungi and as well as notable antioxidant activities based on two chemical assays. They should be the main active compounds in the crude ethanol extract of the aerial parts of this plant. In general, the flavonoid aglycones with relatively low polarity had 
higher antimicrobial and antioxidant activities than the glycosides with high polarity. The study suggests the potential of the $H$. halodendron plant as a source of functional food ingredients with antimicrobial and antioxidant activities. It also provides new data useful for the utilization and further development of $H$. halodendron aerial parts as forage. It is possible that some compounds with a minor content and strong activity have not been isolated and identified from the crude extract. It is also possible that the isolated phenolic compounds might create a synergistic effect that increases the bioactivity. Some compounds may contribute more to the bioactivity. Other issues include the evaluation of the antimicrobial and antioxidant activities of the phenolic compounds in biological tests and their toxicity as well as the establishment of the processes and conditions for extraction and preparation of these compounds in a large scale that need to be further studied.

\section{Acknowledgements}

This work was co-financed by grants from the Hi-Tech R \& D Program of China (2011AA10A202) and the Key Laboratory of Protection and Utilization of Biological Resources in Tarim Basin of Xinjiang, China (BRZD1102).

\section{References}

1. Moure, A.; Cruz, J.M.; Franco, D.; Dominguez, M.; Sineiro, J.; Dominguez, H.; Nunez, M.J.; Parajo, J.C. Natural antioxidants from residual sources. Food Chem. 2001, 72, 145-171.

2. Ames, B.N. Dietary carcinogens and anticarcinogens: Oxygen radical and degenerative diseases. Science 1983, 221, 1256-1264.

3. Ito, N.; Fukushima, S.; Hagiwara, A. Carcinogenicity of butylated hydroxyanisole in F344 rats. J. Natl. Canc. Inst. 1983, 70, 343-352.

4. Ebrahimabadi, A.H.; Ebrahimabadi, E.H.; Djafari-Bidgoli, Z.; Kashi, F.J.; Mazoochi, A.; Batooli, H. Composition and antioxidant and antimicrobial activity of the essential oil and extracts of Stachys inflata Benth from Iran. Food Chem. 2010, 119, 452-458.

5. Ammar, R.B.; Bhouri, W.; Sghaier, M.B.; Boubaker, J.; Skandrani, I.; Neffati, A.; Bouhlel, I.; Kilani, S.; Mariotte, A.-M.; Chekir-Ghedira, L. Antioxidant and free radical-scavenging properties of three flavonoids isolated from the leaves of Rhamnus alaternaus L. (Rhamnaceae): A structure-activity relationship study. Food Chem. 2009, 116, 258-264.

6. Liu, H.; Mou, Y.; Zhao, J.; Wang, J.; Zhou, L.; Wang, M.; Wang, D.; Han, J.; Yu, Z.; Yang, F. Flavonoids from Halostachys caspica and their antimicrobial and antioxidant activities. Molecules 2010, 15, 7933-7945.

7. Bailey, G.S.; Williams, D.E. Potential mechanisms for food related carcinogens and anti-carcinogens. Food Technol. 1993, 47, 105-118.

8. Zhou, L.; Li, D.; Wang, J.; Liu, Y.; Wu, J. Antibacterial phenolic compounds from the spines of Gleditsia sinensis Lam. Nat. Prod. Res. 2007, 21, 283-291.

9. Du, H.; Wang, Y.; Hao, X.; Li, C.; Peng, Y.; Wang, J.; Liu, H.; Zhou, L. Antimicrobial phenolic compounds from Anabasis aphylla. Nat. Prod. Commun. 2009, 4, 385-388. 
10. Wang, J.; Liu, H.; Zhao, J.; Gao, H.; Zhou, L.; Liu, Z.; Chen, Y.; Sui, P. Antimicrobial and antioxidant activities of the root bark essential oil of Periploca sepium and its main component 2-hydroxy-4-methoxy benzaldehyde. Molecules 2010, 15, 5807-5817.

11. Liverio, L.; Puglisi, P.P.; Morazzoni, P.; Bombardelli, E. Antimutagenic activity of procyanidins from Vitis vinifera. J. Stud. Med. Plants 1994, 65, 203-209.

12. Ueda, H.; Yamazaki, C.; Yamazaki, M. Luteolin as an anti-inflammatory and anti-allergic constituent of Perilla frutescens. Biol. Pharm. Bull. 2002, 25, 1197-1202.

13. Sanbongi, C.; Takano, H.; Osakabe, N.; Sasa, N.; Natsume, M.; Yanagisawa, R.; Inoue, K.I.; Sadakane, K.; Ichinose, T.; Yoshikawa, T. Rosmarinic acid in perilla extract inhibits allergic inflammation induced by mite allergen, in a mouse model. Clin. Exp. Allergy 2004, 34, 971-977.

14. Zhang, J.; Shen, Q.; Lu, J.C.; Li, J.Y.; Liu, W.Y.; Yang, J.J.; Li, J.; Xiao, K. Phenolic compounds from the leaves of Cyclocarya paliurus (Batal.) Ijinskaja and their inhibitory activity against PTP1B. Food Chem. 2010, 119, 1491-1496.

15. Fu, K.J. Flora Reipublicae Popularis Sinicae, Tomus 42(1); Science Press: Beijing, China, 1993.

16. Zhang, Q.; Chen, Y.; Li, J.; He, S.; Lin, Y. The assessment and development of wild ligneous feed plants in Xinjiang. Pratacult. Sci. 1996, 13, 1-4.

17. Wang, J.; Gao, H.; Zhao, J.; Wang, Q.; Zhou, L.; Han, J.; Yu, Z.; Yang, F. Preparative separation of phenolic compounds from Halimodendron halodendron by high-speed counter-current chromatography. Molecules 2010, 15, 5998-6007.

18. Wang, J.; Liu, H.; Gao, H.; Zhao, J.; Zhou, L.; Han, J.; Yu, Z.; Yang, F. Antimicrobial and antioxidant activities of the flower essential oil of Halimodendron halodendron. Nat. Prod. Commun. 2011, 6, 1749-1753.

19. Barat, I. Chromosome karyotype analysis of Halimondendron holodendron. Chin. J. Grassland 1996, 18, 23-25.

20. Zhang, M.; Fritsch, P.W.; Cruz, B.C. Phylogeny of Caragana (Fabaceae) based on DNA sequence data from rbcL, trnS-trnG, and ITS. Mol. Phylogenet. Evol. 2009, 50, 547-559.

21. Zhu, Z.J.; Pan, R.; Si, J.Y.; Fu, Y.; Huang, Q.Q. Study on the chemical constituents of Bupleurum bicaule Helm. Nat. Prod. Res. Dev. 2008, 20, 833-835.

22. Shi, J.; Chen, B.; Sun, Z.H.; Hu, C.Q. Studies on flavonoid constituents of Caragana intermedia. Acta Pharm. Sin. 2003, 38, 599-602.

23. Li, L.; Henry, G.E.; Seeram, N.P. Identification and bioactivities of resveratrol oligomers and flavonoids from Carex folliculata seeds. J. Agric. Food Chem. 2009, 57, 7282-7287.

24. Al-Dabbas, M.M.; Kitahara, K.; Suganuma, T.; Hashimoto, F.; Tadera, K. Antioxidant and $\alpha$-amylase inhibitory compounds from aerial parts of Varthemia iphionoides Boiss. Biosci. Biotechnol. Biochem. 2006, 70, 2178-2184.

25. Brandao, M.G.; Nery, C.G.; Mamao, M.A.; Krettli, A.U. Two methoxylated flavone glycosides from Bidens pilosa. Phytochemistry 1998, 48, 397-399.

26. Tang, Y.P.; Wang, Y.; Long, F.C.; Li, Y.F.; Wang, J.H. Flavonoid glycosides from leaves of Ginkgo biloba. Acta Pharm. Sin. 2000, 35, 363-366.

27. Shirataki, Y.; Matsuoka, S.; Komatsu, M.; Ohyama, M.; Tanaka, T.; Iinuma, M. Studies on the constituents of Sophora species. Phytochemistry 1999, 50, 695-701. 
28. Rukachaisirikul, V.; Sukpondma, Y.; Jansakul, C.; Taylor, W.C. Isoflavone glycosides from Derris scandens. Phytochemistry 2002, 60, 827-834.

29. Niu, X.M.; Li, S.H.; Na, Z.; Mei, S.X.; Zhao, Q.S.; Sun, H.D. Studies on chemical constituents of Isodon eriocalyx var. laxiflora. Chin. Tradit. Herb. Drugs 2003, 34, 300-303.

30. Chung, H.S.; Shin, J.C. Characterization of antioxidant alkaloids and phenolic acids from anthocyanin-pigmented rice (Oryza sativa cv. Heugjinjubyeo). Food Chem. 2007, 104, 1670-1677.

31. Tsuchiya, H.; Sato, M.; Miyazaki, T.; Fujiwara, S.; Tanigaki, S.; Ohyama, M.; Tanaka, T.; Iinuma, M. Comparative study on the antibacterial activity of phytochemical flavanones against methicillin-resistant Staphylococcus aureus. J. Ethnopharmacol. 1996, 50, $27-34$.

32. Kaul, T.N.; Middleton, E.J.; Ogra, P.L. Antiviral effect of flavonoids on human viruses. J. Med. Virol. 1985, 15, 71-79.

33. Osawa, K.; Yasuda, H.; Maruyama, T.; Morita, H.; Takeya, K.; Itokawa, H. Isoflavanones from the heartwood of Swartzia polyphylla and their antibacterial activity against cariogenic bacteria. Chem. Pharm. Bull. 1992, 40, 2970-2974.

34. Huang, D.J.; Ou, B.; Prior, R.L. The chemistry behind antioxidant capacity assays. J. Agric. Food Chem. 2005, 53, 1841-1856.

35. Silva, M.M.; Santos, M.R.; Caroco, G.; Rocha, R.; Justino, G.; Mira, L. Structure-antioxidant activity relationships of flavonoids: A re-examination. Free Radical Res. 2002, 36, 1219-1227.

36. Wojdylo, A.; Oszmianski, J.; Czemerys, R. Antioxidant activity and phenolic compounds in 32 selected herbs. Food Chem. 2007, 105, 940-949.

37. Uriarte-Pueyo, I.; Calvo, M.I. Structure-activity relationships of acetylated flavone glycosides from Galeopsis ladanum L. (Lamiaceae). Food Chem. 2010, 120, 679-683.

38. Wolfe, K.L.; Liu, R.H. Structure-activity relationships of flavonoids in the cellular antioxidant activity assay. J. Agric. Food Chem. 2008, 56, 8404-8411.

39. Bors, W.; Heller, W.; Michel, C.; Saran, M. Radical chemistry of flavonoid antioxidants. Adv. Exp. Med. Biol. 1990, 264, 165-170.

40. Bors, W.; Heller, W.; Michel, C.; Saran, M. Flavonoids as antioxidants: determination of radical-scavenging efficiencies. Method. Enzymol. 1990, 186, 343-355.

41. Benavente-Garcia, O.; Castillo, J.; Marin, F.R.; Ortuno, A.; Del Rio, J.A. Uses and properties of citrus flavonoids. J. Agric. Food Chem. 1997, 45, 4505-4515.

42. Pietta, P.G. Flavonoids as antioxidants. J. Nat. Prod. 2000, 63, 1035-1042.

43. Chen, Z.Y.; Chan, P.T.; Ho, K.Y.; Fung, K.P.; Wang, J. Antioxidant activity of natural flavonoid is governed by number and location of their aromatic hydroxyl groups. Chem. Phys. Lipids 1996, 79, 157-163.

44. Langfied, R.D.; Scarano, F.J.; Heitzman, M.E.; Kondo, M.; Hammond, G.B.; Neto, C.C. Use of a modified microplate bioassay method to investigate antibacterial activity in the Peruvian medicinal plant Peperomia galioides. J. Ethnopharmacol. 2004, 94, 279-281.

45. Abe, K.; Matsuki, N. Measurement of cellular 3-(4,5-dimethylthiazol-2-yl)-2,5-diphenyltetrazolium bromide (MTT) reduction activity and lactate dehydrogenase release using MTT. Neurosci. Res. 2000, 38, 325-329.

46. Sakuma, M. Probit analysis of preference data. Appl. Entomol. Zool. 1998, 33, 339-347. 
47. Liu, H.; Wang, J.; Zhao, J.; Lu, S.; Wang, J.; Jiang, W.; Ma, Z.; Zhou, L. Isoquinoline alkaloids from Macleaya cordata active against plant microbial pathogens. Nat. Prod. Commun. 2009, 4, 1557-1560.

48. Ono, M.; Oda, E.; Tanaka, T.; Iida, Y.; Yamasaki, T.; Masuoka, C.; Ikeda, T.; Nohara, T. DPPH radical-scavenging effect on some constituents from the aerial parts of Lippia triphylla. J. Nat. Med. 2008; 62, 101-106.

(C) 2012 by the authors; licensee MDPI, Basel, Switzerland. This article is an open access article distributed under the terms and conditions of the Creative Commons Attribution license (http://creativecommons.org/licenses/by/3.0/). 